\title{
SITES DA INTERNET: UMA POSSIBILIDADE DE RECURSO PARA O ENSINO DE EDUCAÇÃO FINANCEIRA
}

\section{INTERNET SITES: A POSSIBILITY OF RESOURCE FOR THE TEACHING OF FINANCIAL EDUCATION}

\author{
Leandro Oliveira de Carvalho ${ }^{1}$
}

Secretaria Municipal de Educação de Ibiapina

\author{
Nilton José Neves Cordeiro ${ }^{2}$ \\ Universidade Estadual Vale do Acaraú - UVA \\ Márcio Nascimento da Silva ${ }^{3}$ \\ Universidade Estadual Vale do Acaraú - UVA
}

\begin{abstract}
Resumo
Entendendo que a temática Educação Financeira é de relevância para toda sociedade e algo recente no cenário mundial, impulsionada por pesquisas feitas pela Organização para Cooperação e Desenvolvimento Econômico (OCDE), o assunto tomou força no Brasil nos últimos dez anos, impactando, inclusive, no ambiente escolar, algo refletido na atual Base Nacional Comum Curricular (BNCC). Devido ao novo caráter da Educação Financeira nas escolas, os professores ainda carecem de fontes e materiais adequados e de boa qualidade, que proporcionem um processo de ensino acertado e enriquecedor. Face a esse cenário, este artigo objetiva propor a utilização de sites confiáveis da internet como ferramenta de apoio aos professores na construção de atividades que potencializem a aprendizagem e busquem formar alunos financeiramente educados. Nessa perspectiva, através de uma revisão bibliográfica, fora sinalizada a importância da Educação Financeira para uma sociedade mais consciente, apontouse uma gama diversificada na literatura sobre a conceituação de Educação Financeira e destacou-se a internet - se usada com a devida cautela - como uma ferramenta de pesquisa útil e poderosa. A partir disso, fora feita uma busca exploratória na internet de sites de entidades reconhecidamente tradicionais e confiáveis que tratassem do tema Educação Financeira, constatando-se que há uma pluralidade de materiais sobre finanças tratados de uma forma clara e acessível ao público em geral. A pesquisa mostra que é possível trabalhar Educação Financeira com o uso de sites, dependendo do objetivo que se deseja atingir e propõe estratégias de ensino que levem Educação Financeira para o meio escolar, buscando formas para iniciar a preparação do indivíduo no enfrentamento dos desafios do mundo das finanças. Destaca ainda que, para a efetivação desse tipo de ensino, as instituições escolares precisam promover cursos formativos que possibilitem a capacitação e qualificação dos professores no que diz respeito à inserção do conteúdo em sala de aula.
\end{abstract}

Palavras-chave: Educação Financeira; Internet; Site; Ensino.

\footnotetext{
Abstract

${ }^{1}$ Leandrooliv279@gmail.com

2nilton76@gmail.com

3marcio@matematicauva.org
} 
Taking into considerarion that the Financial Education topic is of relevance to the whole society and that is also something recent in the world scenario, driven by research done by the Organization for Economic Cooperation and Development (OECD), the subject has taken force in Brazil in the last ten years, impacting school environment, something reflected in the current Common National Curricular Base. Due to the new aspect of Financial Education in schools, teachers still lack adequate and good quality materials and supplies that provide a successful and enriching teaching process. Given this scenario, this article aims to propose the use of reliable internet sites as a tool to support teachers in the construction of activities that enhance learning and seek to train financially educated students. In this perspective, through a bibliographical review, the importance of Financial Education for a more conscious society was signaled, a diversified range was identified in the literature on the conceptualization of Financial Education in addition to the emphasis on the internet - if used cautiously - as a useful and powerful search tool. As a result, an exploratory search on the Internet for sites of recognized and traditional entities dealing with the subject of Financial Education was made, and it was found that there is a huge range of finance materials treated in a clear and accessible manner to the general public. The research shows that it is possible to work Financial Education with the use of websites, depending on the objective that is desired and proposes teaching strategies that lead Financial Education to the school environment, looking for ways to begin the preparation of the individual in facing the challenges of the world of finance. It is also worth noting that for the implementation of this type of education, school institutions need to promote training courses that enable the qualification and qualification of teachers with regard to the insertion of content in the classroom.

Keywords: Financial Education; Internet; Site; Teaching.

\section{Introdução}

Nos dias de hoje é comum encontrar jornais televisivos falando de cotação do dólar, taxa de juros, bolsa de valores e endividamento. Também é habitual ver pessoas comentando sobre contas a pagar, cartão de crédito, prestações, financiamentos e outras coisas relacionadas à dinheiro. Todas estas questões perpassam por uma seara que vem ganhando mais destaque, inclusive no seio da escola: a Educação Financeira (EF).

Infelizmente muitas pessoas não possuem um conhecimento apropriado quando se fala em Educação Financeira. Neste sentido, Silva e Powell (2015) relatam que a Organização para Cooperação e Desenvolvimento Econômico (OCDE), divulgando resultados de pesquisas em seu relatório Improving Financial Literacy: Analysis of Issues and Policie - ver OCDE (2005) -, apontou populações até mesmo de países desenvolvidos, como Estados Unidos, Japão e Reino Unido, com baixo conhecimento e compreensão financeiros, independentemente dos níveis de renda e escolaridade.

Esta constatação, aliada ao mundo consumista em que vivemos, faz com que se acenda um alerta de cuidado, sendo importante se ter ao menos o mínimo de conhecimento em finanças 
para saber lidar, por exemplo, com situações do dia a dia e até mesmo com "armadilhas" trazidas pelo comércio/mercado. Daí a relevância do tema.

Segundo Kiyosaki e Lechter (2000, p.147) "Temos que ensinar aos jovens as habilidades acadêmicas e financeiras de que precisarão não só para sobreviver, mas para desenvolver-se no mundo com que se deparam". Entendemos isso como verdadeiro, mas reforçamos que tais habilidades devem ir sendo solidificadas nos indivíduos o quanto antes, já mesmo a nível escolar.

Atualmente muitos problemas enfrentados pela sociedade estão relacionados à falta de consciência quanto aos gastos diários do cidadão. Assim, a apropriação de conhecimentos acerca do mundo financeiro possibilita formas mais eficazes de administração do dinheiro, seja nas compras, nas despesas diárias, em um investimento ou em um planejamento familiar, o indivíduo passa a ser mais consciente e organizado, encontrando formas mais inteligentes para lidar com situações que envolvem dinheiro.

Com o propósito de trazer a temática para o ensino, esse trabalho procura expor materiais e recursos gratuitos encontrados em sites da internet que podem servir como ferramentas para a Educação Financeira, contribuindo para a disseminação do assunto e esclarecimento da sua importância na Educação.

Entendendo que a escola é um espaço onde a Educação Financeira pode e deve ser trabalhada, a presente pesquisa procura mostrar que é possível explorar o tema nas instituições escolares usando a internet como instrumento, pois entende-se que falar sobre a Educação Financeira com o uso de sites pode proporcionar uma contribuição importante nos processos de ensino e aprendizagem, tanto para o professor quanto para o aluno.

\section{O que é Educação Financeira?}

Uma característica marcante da sociedade capitalista atual é a presença maciça do consumismo, o que pode impactar diretamente na situação financeira dos indivíduos e famílias, problema que pode agravar se as pessoas não possuem ou não se preocupam em se informar sobre temas relacionados ao dinheiro.

Neste sentido é relatado em OCDE (2005) que inúmeras pessoas em vários países não só precisam dos conhecimentos e competências necessários para tratar de modo adequado com suas finanças pessoais, mas também ignoram a sua própria importância.

Diante disso, faz-se imprescindível a abordagem do tema na sociedade e uma das formas seria levando o assunto às instituições educacionais, pois a própria Base Nacional Comum 
Curricular (BNCC) para Educação Infantil e Ensino Fundamental, homologada no final de 2017, traz Educação Financeira como obrigatória já nos primeiros anos do Ensino Fundamental, sendo essencialmente abordada em Matemática.

Segundo a Organização para Cooperação e Desenvolvimento Econômico

\begin{abstract}
Educação Financeira é o processo mediante o qual os indivíduos e as sociedades melhoram a sua compreensão em relação aos conceitos e produtos financeiros, de maneira que com informação, formação e orientação possam desenvolver os valores e as competências necessários para se tornarem mais conscientes das oportunidades e riscos neles envolvidos e, então, poderem fazer escolhas bem informadas, saber onde procurar ajuda, adotar outras ações que melhorem o seu bem-estar e, assim, tenham a possibilidade de contribuir de modo mais consistente para a formação de indivíduos e sociedades responsáveis, comprometidos com o futuro. (OCDE, 2005, p.2)
\end{abstract}

Utilizando um conceito de EF mais voltado para a questão do ensino, pode-se admitir que

Educação Financeira é um processo educativo que, por meio de aplicação de métodos próprios, desenvolve atividades para auxiliar os consumidores a orçar e gerir a sua renda, a poupar e a investir; são informações e formações significativas para que um cidadão exerça uma atividade, trabalho, profissão e lazer, evitando tornarem-se vulneráveis às armadilhas impostas pelo capitalismo. (NEGRI, 2010, p.19, citado por CORDEIRO, COSTA e SILVA, 2018, p. 71)

Educação Financeira ainda é pouco discutida, mas vem ganhando relevância no cenário educacional, instruindo e estimulando o indivíduo a ser mais consciente de ações como sensatez no uso do dinheiro, financiamento, endividamento, consumo e renda, pois a falta de informação sobre esses assuntos torna o indivíduo alvo fácil de manipulações.

É importante destacar que esse tipo de educação proporciona ao indivíduo adequar os seus objetivos à sua renda, através de conceitos e atitudes que o fazem mudar sua forma de agir diante de situações que envolvem dinheiro. Entretanto, não basta apenas que o indivíduo tome consciência dos princípios de Educação Financeira, mas é necessário que ele e sua família a introduzam no seu estilo de vida, pois é bem difícil manter uma vida financeira estável quando não há essa sintonia no seio familiar.

A família precisa de união para fazer com que a situação financeira melhore. É necessário a união de todos os membros, todos devem saber exatamente a real situação que a família se encontra para que ninguém exceda o limite financeiro. Não se deve negligenciar a importância deste controle financeiro familiar. As consequências são inúmeras vezes desastrosas e na maioria dos casos acarretam grandes períodos de dificuldades. (ORIENTE, LIMA e RIBEIRO, 2015, p.6) 
Educação Financeira está associada à forma e o processo de como o sujeito adquire conceitos financeiros, buscando desenvolver um senso crítico em relação à tomada de decisões.

Vale enfatizar que educar-se financeiramente é também conseguir relacionar sua situação financeira com a realidade na qual está, inclusive, levando em conta o caráter cultural do indivíduo e o meio social ao qual está inserido.

Compreender EF é ter conhecimento para potencializar um futuro financeiramente robusto através do planejamento. O mundo em que vivemos é uma grande sociedade de consumo e cuidar do nosso dinheiro demanda disciplina e comprometimento constantes.

Educação financeira pode qualificar os consumidores a serem melhores compradores, permitindo-os obter bens e serviços a custos menores. Este processo efetivamente aumenta o poder de compra real do consumidor e provê maiores oportunidades para consumir mais, poupar ou investir. Além do mais, a educação financeira pode auxiliar as pessoas a obter ganhos de conhecimentos necessários para criar orçamentos familiares, iniciar planos de poupança, gerenciamento de débito e formular decisões estratégicas de investimentos para a sua aposentadoria ou para a educação de seus filhos. (GREENSPAN, 2005, p.65, citado por MATTA e AMARAL, 2007, p.60)

Em vista de todos esses benefícios que a Educação Financeira proporciona é necessário que esse conhecimento seja efetivamente ensinado e

A melhor forma de ser abordado o tema seria nas escolas com o apoio da família para a prática, assim os alunos entenderiam que a educação financeira não visa o enriquecimento e sim a conscientização para que o jovem desenvolva atitudes para saberem lidar com o dinheiro, podendo ter uma vida segura e confortável. (STEPHANI, 2005, p.12)

Kliemann, Silva e Dullius (2011, p.5) ao citarem Kern (2009, p.114) dizem que a “[...] inclusão de Educação Financeira na escola pública demanda um longo trabalho de análise das necessidades básicas de cada realidade.", indo ao encontro do indicado acima, inclusive no que tange ao ensino de EF ser uma importante ferramenta de inclusão social.

Através da família e da escola é possível tornar a sociedade mais consciente financeiramente, afinal, estes são os pilares que sustentam a base para a construção de um mundo mais digno de se viver.

\section{A Internet como fonte de pesquisa}


Durante muito tempo, quando se buscava informação, basicamente a única fonte de conhecimento existente era o livro, mas, atualmente, com os avanços tecnológicos e o advento da rede mundial de computadores - a internet -, essa realidade tem mudado.

Hoje a internet é bastante utilizada quando se necessita fazer uma pesquisa nas mais diversas áreas, proporcionando informação sobre uma infindável gama de temas. Essa facilidade está cada vez mais presente na vida das pessoas, influenciando na forma de agir e pensar dos indivíduos.

\begin{abstract}
A Internet representa uma novidade nos meios de pesquisa. Trata-se de uma rede mundial de comunicação via computador onde as informações são trocadas livremente entre todos. Sem dúvida, a Internet representa uma revolução no que concerne à troca de informação. A partir dela, todos podem informar a todos. Mas se ela pode facilitar a busca e a coleta de dados, ao mesmo tempo oferece alguns perigos. $\mathrm{Na}$ verdade, grande parte das informações passadas por essa rede não têm critérios de manutenção de qualidade da informação. (KAUARK, MANHÃES e SOUZA 2010, p.57)
\end{abstract}

Entretanto, é necessária prudência, há de se ter critério no uso da internet. É preciso filtrar os conteúdos expostos na mesma, verificando se a procedência é segura para assim poder usar informações confiáveis. Cortella (2009) alerta que

[...] Não se deve confundir informação com conhecimento. A Internet, entre as mídias contemporâneas, é a mais fantástica e estupenda ferramenta para acesso à informação; no entanto transformar informação em conhecimento exige, antes de tudo, critérios de escolha e seleção, dado que o conhecimento (ao contrário da informação) não é cumulativo, mas seletivo. (p.24)

Com o acesso à internet cada vez mais usual, difundido e barato, a escola também faz uso dessa importante ferramenta, tornando as aulas mais dinâmicas e interativas.

Estamos vivenciando um momento de grandes transformações e avanços tecnológicos. A sociedade está mudando em um ritmo acelerado, surge a necessidade de contínua atualização em todas as esferas sociais, principalmente no âmbito escolar. Muitas formas de ensinar hoje, já não se justificam mais. As tecnologias, principalmente o computador e a Internet adentram as salas de aula como uma ferramenta na mediação do processo de conhecimento. A escola precisa compreender e incorporar a linguagem virtual da Internet, e integrar esta tecnologia de forma inovadora como fonte de pesquisa e ferramenta de trabalho, tornando-a um elemento que poderá contribuir para uma maior vinculação entre os contextos de ensino e as culturas que se desenvolvem também fora do âmbito escolar. (RAMOS e COPPOLA, 2009, p.3) 
Também por estar presente no cotidiano dos alunos, o professor, como educador, deve pensar em novas formas de ensino - que envolvam o uso da internet - para tornar suas aulas mais dinâmicas, interessantes e produtivas.

\begin{abstract}
A internet é hoje uma ferramenta indispensável no processo de ensino e aprendizagem, pois ela proporciona uma interação efetiva entre professores e alunos, possibilitando assim novas propostas de trabalho. Ela consegue fazer uma ponte entre a escola e o mundo exterior aumentando assim a comunicação entre a escola, os alunos, os pais e toda a comunidade, além de proporcionar um trabalho mais divertido, através do uso da internet o aluno deixa de ser um mero receptor e passa a fazer parte ativamente do processo ensino-aprendizagem. Para o professor, o uso da internet é uma forma de aproximação dele e do aluno, além de proporcionar um acesso mais rápido a notícias científicas e educacionais atualizadas que podem ser utilizadas em sala de aula. (RAMOS e COPPOLA, 2009, p.6)
\end{abstract}

A BNCC reforça este pensamento ao considerar a internet como um recurso midiático importante para práticas em sala de aula, podendo colaborar para o trabalho pedagógico. Essa contribuição pode ser através de sites, blogs, artigos, vídeos entre outros materiais virtuais pedagógicos. Porém, para uso adequado, é necessária uma boa orientação e, para isso, os professores precisam ter acesso a capacitações e formações permanentes sobre essas novas tecnologias, pois muitos não sabem fazer o uso adequado.

\footnotetext{
A Internet, ao tornar-se mais e mais hipermídia, começa a ser um meio privilegiado de comunicação de professores e alunos, já que permite juntar a escrita, a fala e proximamente a imagem a um custo barato, com rapidez, flexibilidade e interação até pouco tempo impossíveis. (MORAN, 1997)
}

Assim percebe-se quão relevante pode ser a internet no que diz respeito à educação, tanto pela riqueza de informação nela presente, quanto pela possibilidade de integração virtual. Partindo desses pressupostos, foca-se a atenção para as múltiplas alternativas que a internet é capaz de proporcionar para a Educação Financeira.

O acesso à sites pode sanar dúvidas e trazer dicas sobre as melhores formas de lidar com o dinheiro. Esses benefícios podem vir através de vídeos, artigos, livros, relatos de comportamentos e situações que envolvam finanças, entrevistas com profissionais da área da Educação Financeira, softwares, quadrinhos com temas voltados para finanças, dentre outros. Além disso, pode-se encontrar uma linguagem acessível e clara para diversos públicos e a possibilidade de segmentação do seu público alvo desejado.

Esses recursos podem ser trabalhados nas escolas como acessório pedagógico através de palestras, seminários e até mesmo no dia a dia na sala de aula. Cabe ao professor apropriar- 
se dos conhecimentos e materiais oferecidos por esses sites para conseguir aprimorar ainda mais as suas aulas.

\section{Alguns sites que tratam do tema Educação Financeira}

Nesta seção serão apresentados dois sites que possuem uma grande variedade de informações sobre Educação Financeira e que podem ser utilizados como material de apoio para professores e alunos.

\section{MEU BOLSO FELIZ}

O site Meu Bolso Feliz (www.meubolsofeliz.com.br) é uma iniciativa do Serviço de Proteção ao Crédito - SPC Brasil - que, com mais de 55 anos de mercado, é considerada uma das maiores empresas da América Latina que trabalham com sistema de informações creditícias de pessoas físicas e jurídicas, com dados do comércio nacional.

O site Meu Bolso Feliz é bem vasto, oferecendo serviço de orientação financeira, com linguagem simples e, ao mesmo tempo, instrutiva e didática, possibilitando um bom entendimento dos assuntos. Ao navegar é possível ter acesso a inúmeros recursos de visualização, respostas e resultados imediatos para as necessidades e dúvidas do internauta.

O site ainda possui reportagens, entrevistas com especialistas, como também muitas dicas sobre consumo, que podem contribuir para formação e amadurecimento financeiros dos usuários. O mesmo traz dicas e alternativas sobre possíveis gastos, educação dos filhos com foco no planejamento financeiro e economia no dia a dia. Também oferece simuladores que ajudam o internauta a cuidar do orçamento e investimento, com o objetivo de saber mais detalhes sobre prazos e condições financeiras, diagnósticos financeiros, investimentos e boa compra, fazendo o indivíduo entender melhor o mundo das finanças.

Um dispositivo interessante oferecido no site são os testes para que se descubra como está a forma de encarar o mundo das finanças, levando-o a refletir sobre questões como "Você é um comprador impulsivo?", "Você sabe estabelecer metas?", "Você é um consumidor consciente?", dentre outras. Nessa ferramenta é proposto um questionário relacionado a temas de Educação Financeira, o qual será respondido pelo internauta.

O site também disponibiliza vídeos, com dicas para tornar a vida financeira organizada, além de mostrar como o descontrole com contas pode se tornar um vilão na hora de fechar o mês sem dívidas. 
Destacam-se as tirinhas, com abordagem de temas voltados para Educação Financeira potencialmente eficientes para atrair a atenção da criança.

Figura 1 - Categoria Tirinhas do site Meu Bolso Feliz.

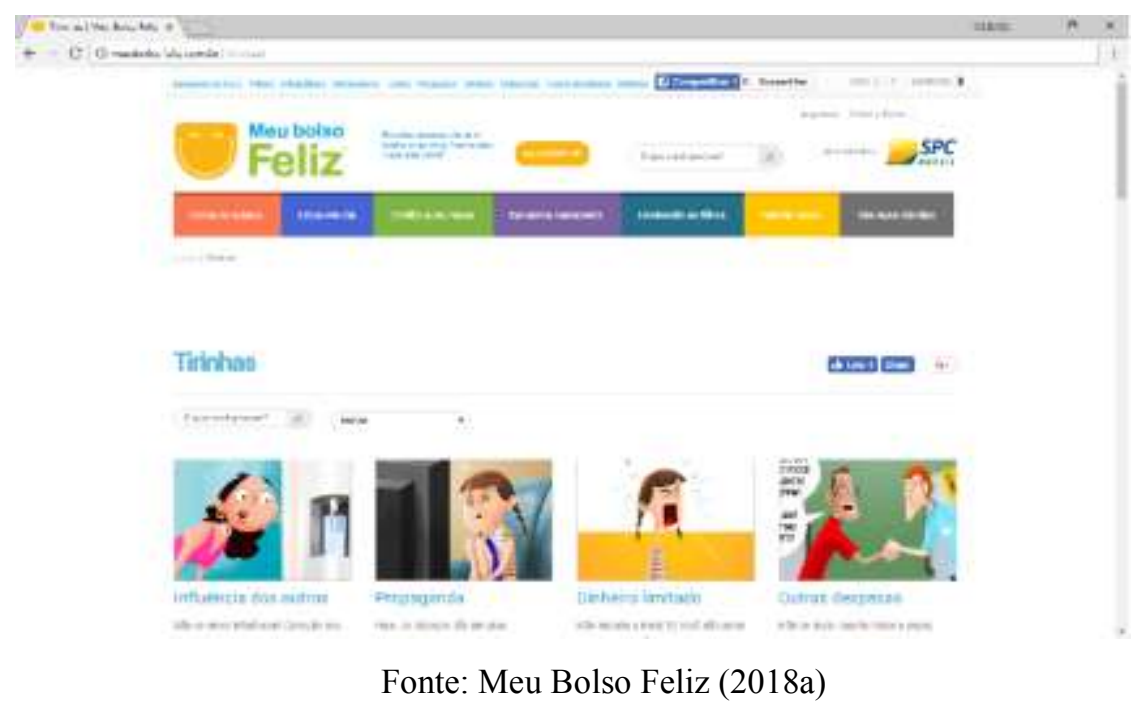

A Figura 1 mostra algumas das tirinhas oferecidas pelo site, com destaque para os temas "Influência dos outros", "Propaganda", "Dinheiro Limitado", "Outras despesas", "Consórcio", entre outros.

\section{MEU BOLSO EM DIA}

O site Meu Bolso em Dia (www.meubolsoemdia.com.br) é uma iniciativa da Federação Brasileira de Bancos (FEBRABAN), que se define como "[...] a principal entidade representativa do setor bancário brasileiro", sendo "[...] uma associação sem fins lucrativos que tem o compromisso de fortalecer o sistema financeiro e suas relações com a sociedade e contribuir para o desenvolvimento econômico, social e sustentável do País". O site propõe a prestação de serviço de Educação Financeira, contribuindo para que a sociedade administre com mais responsabilidade sua vida financeira.

O site foi lançado em abril de 2010 com a interessante proposta de oferecer à sociedade materiais educacionais sobre os mais variados assuntos no que se refere à Educação Financeira. O mesmo procura apresentar novas formas de lidar com as finanças pessoais, buscando promover um consumo consciente e inteligente, tendo como uma das principais metas orientar a administração do orçamento mensal e ampliar a compreensão sobre o sistema financeiro. 
Possui ainda dicas de investimento, educação, como comprar melhor, emprego, entendendo o banco, entre outras.

Uma das ferramentas disponibilizadas pelo site são os simuladores financeiros, softwares que oferecem serviços para que o indivíduo possa administrar bem o seu dinheiro, destacando o Jimbo, um programa exclusivo de gestão financeira do site, disponível para computador e smartphone. Com uma interface simples e dinâmica, possui ainda 15 funcionalidades interessantes e está disponível para download gratuito no site, permitindo o lançamento de despesas e rendas, cadastro de alertas de vencimento de contas, além de gerar relatórios para visualização em modo gráfico ou extrato.

Figura 2 - Categoria Apps e Games do site Meu Bolso em Dia

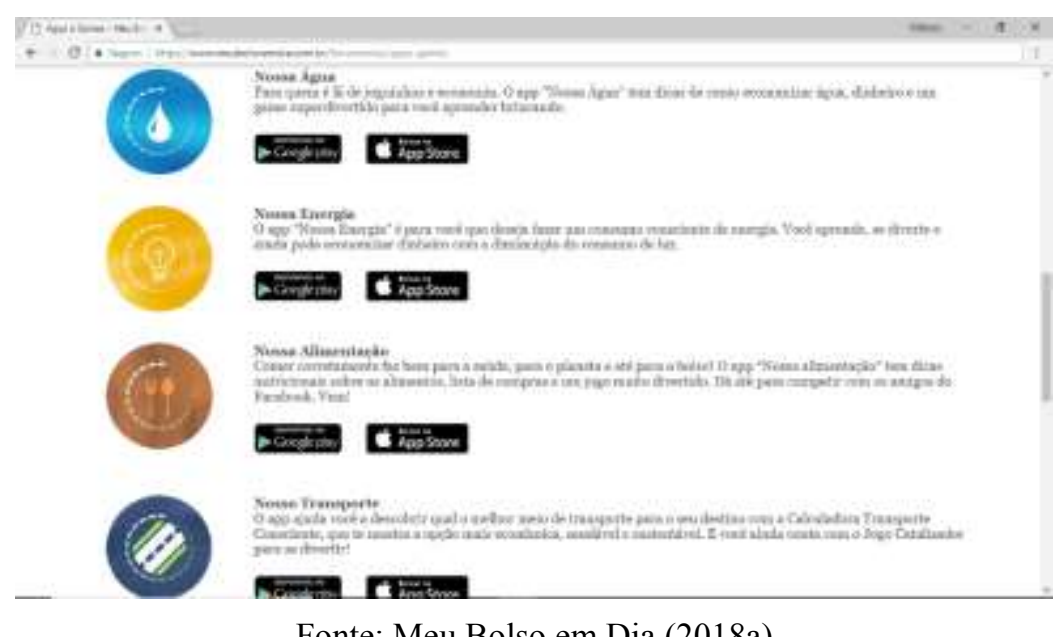

Fonte: Meu Bolso em Dia (2018a)

Na Figura 2 é mostrada a categoria Apps que além de ter o Jimbo, conforme descrito anteriormente, apresenta como destaques as ferramentas Nossa Água, Nossa Energia, Nossa Alimentação e Nosso Transporte, trazendo jogos abordando temas específicos e motivando à economia de recursos, o consumo consciente, alimentação saudável e a questão da sustentabilidade, podendo ser baixados gratuitamente.

\section{Utilizando os sites no ensino de Educação Financeira}

Aqui serão propostas estratégias de ensino de Educação Financeira inspiradas nos sites descritos anteriormente e que podem ser adotadas nas escolas com o objetivo de mostrar como o professor pode utilizar alguns dos recursos oferecidos por estes sites. 


\section{MEU BOLSO FELIZ - FERRAMENTA INFOGRÁFICO}

O infográfico é um desenho ou imagem que, com a ajuda de um texto, explica ou informa sobre um assunto que não é bem compreendido apenas com um texto. No site Meu Bolso Feliz é possível encontrar muitos infográficos voltados para o tema de Educação Financeira, artifício capaz de chamar a atenção do aluno para aquilo que ser quer informar.

Figura 3 - Infográfico: Tipos de dívidas

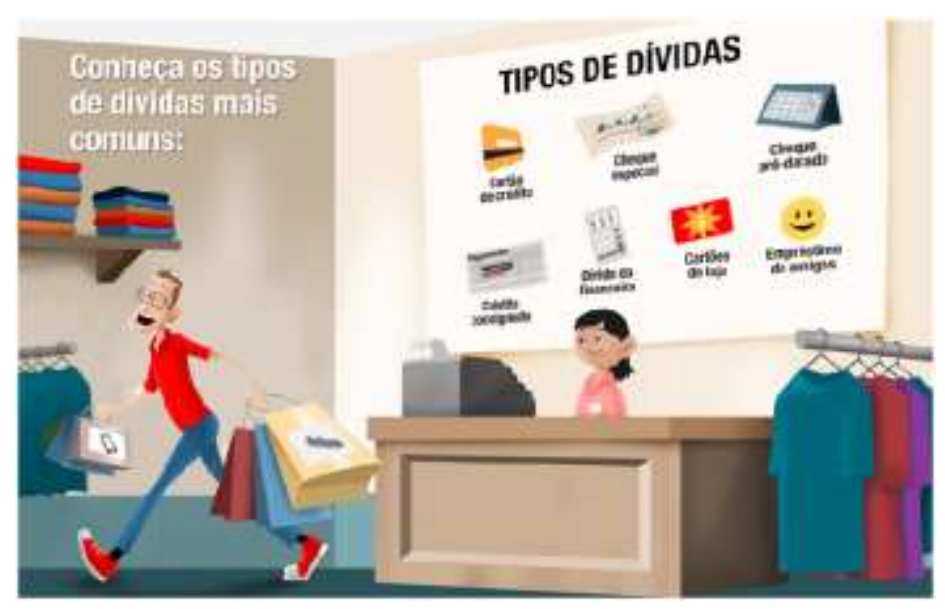

Fonte: Meu Bolso Feliz (2018b)

A situação apresentada na Figura 3 pode ser levada para uma sala de aula do Ensino Médio, por exemplo. Uma discussão em cima das questões abordadas no infográfico poderá ser feita por meio de perguntas aos educandos, tomando depoimentos, motivando debates e simulações de situações cotidianas. A partir deste infográfico é possível trabalhar assuntos como no que consiste e como funciona o crédito consignado e a sua disseminação no Brasil, nos últimos anos, tanto para trabalhadores quanto aposentados. Também há espaço para trazer a temática cartão de crédito, perguntando aos alunos se pessoas nas suas famílias o utilizam e se sabem como funciona a sua utilização. Além disso seria momento oportuno de abordar a temática do alto custo do uso do financiamento a partir do cartão de crédito, trazendo à tona a questão da mudança desde 2017 do chamado rotativo. O contexto do cheque especial é igualmente pertinente ser tocado, inclusive alertando que há instituições financeiras que chegam a cobrar juros anuais de até três dígitos quando o cliente o utiliza.

Dessa forma, há espaço para se criar um ambiente criativo no desenvolvimento de várias questões que permeiam a vida do aluno e de sua família, assim como da sociedade. 


\section{MEU BOLSO EM DIA FERRAMENTA - TABELA DIA A DIA}

No site meu Bolso em Dia na categoria “Tabelas Dia a Dia” é possível fazer download no formato PDF (Formato Portátil de Documento) de um bloco de notas (Figura 6) com o objetivo de fazer anotações de gastos diários.

Figura 4 - Tabelas Dia a Dia.

\begin{tabular}{|c|c|c|}
\hline Mes: & Tipo de Despesas: & Forma de Pagamento: \\
\hline Dia: & Valor(RS): & \\
\hline & & \\
\hline & & \\
\hline & & \\
\hline & & \\
\hline & & \\
\hline & & \\
\hline & & \\
\hline & & \\
\hline & & \\
\hline & & \\
\hline & & \\
\hline & & \\
\hline & & \\
\hline & & \\
\hline
\end{tabular}

Fonte: Meu Bolso em Dia (2018b)

Através da ferramenta exposta na Figura 4, poder-se-ia trabalhar com alunos do Ensino Fundamental - Anos Finais, objetivando nutrir a ideia de organização das contas diárias, bem como ter à mão um lembrete das compras do dia. Nessa proposta de ensino busca-se incentivar a cultura tanto da construção de orçamentos individuais e familiares quanto do planejamento financeiro. É possível fazer uma simulação com os alunos das despesas individuais, fazendo com que cada aluno calcule as suas - ou de sua família - despesas diárias e procure fazer um planejamento pensando em economia e consumo consciente. Para concluir a atividade, apresentam-se e discutem-se as simulações feitas, através de debates em grupos, por exemplo.

\section{Considerações Finais}


O tema Educação Financeira ainda precisa ser devidamente difundido na sociedade. A escola como instituição responsável por educar crianças, jovens e adultos, se constitui como ambiente adequado para apropriação deste conhecimento. Para que isso ocorra, faz-se necessário que as instituições de ensino se equipem com recursos metodológicos para a efetiva divulgação desse assunto.

Com a homologação da Base Nacional Comum Curricular, a Educação Financeira passa a ser obrigatória para crianças do ensino fundamental e deverá ser abordada em Matemática, podendo ser contemplada em outras áreas, como Ciências da Natureza, História e Geografia. Com o ano de 2018 para discussão da inserção da BNCC e, a partir de 2019, de fato, a sua implementação em sala de aula, há a necessidade de buscar informações sobre esse conhecimento por parte dos professores, nesse sentido o presente trabalho se converte em suporte para o educador.

Essa pesquisa tem como objetivo propor uma forma de difundir o conhecimento acerca de Educação Financeira através de recursos que podem ser encontrados em sites de instituições tradicionais do meio financeiro que tratam do assunto, ressaltando que existem muitos outros sites interessantes que também podem ser utilizados no ensino de Educação Financeira nas escolas, como por exemplo, os sites "Vida e Dinheiro", "Educação Financeira para Todos", “Como Investir", "Finanças Femininas", "Banco Central do Brasil”, entre outros.

Percebe-se que o uso de sites que tratam de finanças pode vir a ser uma ferramenta de grande importância para a Educação Financeira nas escolas, pois eles oferecem uma grande variedade de recursos para seu ensino, os quais podem ser direcionados ao público em geral. A escola, como instituição responsável pela formação do indivíduo, é um excelente ambiente para a utilização dessas ferramentas.

Entretanto, é necessário que os professores saibam selecionar os conteúdos adequados para o ensino, além, claro, que o próprio educador saiba como utilizar tais recursos. Nesse sentido, faz-se necessário que as instituições de ensino ofereçam formações especializadas para os professores, fundamentadas no uso dessas novas tecnologias e na relevância da presença do tema "Educação Financeira” para os conteúdos escolares.

\section{Referências}

CORDEIRO, N. J. N.; COSTA, M. G. V.; SILVA, M. N. da. Educação Financeira no Brasil: uma perspectiva panorâmica. Ensino da Matemática em Debate. v. 5, n. 1, pp. 69-84, 2018. 
CORTElla, M. S. Não Nascemos Prontos! - Provocações Filosóficas. Editora Vozes, 19a . Ed., 2009.

GREEENSPAN, A. The importance of financial education today. Social Education, v.69, n.2, p. 64-67, Mar. 2005.

KAUARK, F. S.; MANHÃES, F. C.; SOUZA, C.H.M. Metodologia da Pesquisa: um guia prático. Editora Via Litterarum. Itabuna/Bahia, 2010.

KERN, D. T. B. Uma reflexão sobre a importância de inclusão de educação financeira na escola pública.. Dissertação (Mestrado). UNIVATES. Lajeado: RS, 2009.

KIYOSAKI, R. T.; LECHTER, S.L. Pai Rico, pai pobre: o que os ricos ensinam a seus filhos sobre dinheiro. Ed. $66^{\circ}$, Rio de Janeiro: Elsevier, 2000.

KLIEMANN, G.L.; SILVA, P.F.; DULLIUS, M.M. Relevância da Matemática Financeira no Ensino Fundamental. Revista Destaques Acadêmicos, Ano 3, N. 4, 2011 CETEC/UNIVATES. Vale do Taquari e Rio Pardo. Rio Grande do Sul.

MATTA, R. O. B.; AMARAL, S. A. Oferta e demanda de informação financeira pessoal: o programa de Educação Financeira do Banco Central do Brasil e os universitários do Distrito Federal. IX Encontro Nacional de Pesquisa em Ciência da Informação. Universidade de São Paulo: São Paulo, 2007.

MEU BOLSO FELIZ. Disponível em: < http://meubolsofeliz.com.br/tirinhas/>. Acessado em 01/08/18, 2018a.

Disponível em: < http://meubolsofeliz.com.br/infograficos/tipos-de-dividas/ > .

Acessado em: 30/07/18, 2018b.

MEU BOLSO EM DIA. Disponível em:

https://www.meubolsoemdia.com.br/Ferramentas/apps-games. Acessado em: 01/08/18, 2018a.

. Disponível em: < https://www.meubolsoemdia.com.br/output/aquivos-

downloads/tabeladiadia-bloquinho-03-11-2015-00-13-00.pdf $>$. Acessado em: 12/03/18, $2018 b$.

MORAN, J. M. Como utilizar a internet na educação. Ciência da Informação, v. 26, n. 2, 1997.

NEGRI, A. L. L. Educação para o Ensino Médio da Rede Pública: uma proposta inovadora. 2010. 73f. Dissertação (Mestrado). Centro Universitário Salesiano de São Paulo: UNISAL, 2010.

ORGANIZAÇÃO DE COOPERAÇÃO E DE DESENVOLVIMENTO ECONÔMICOOCDE. Recommendation on Principles and Good Practices for Financial Eduction and Awareness. OCDE, 2005. Disponível em: http://www.oecd.org/finance/financial-education/35108560.pdf Acesso em: 07. fev. 2018. 
ORIENTE, A. C. N.; LIMA, L.L.F; RIBEIRO, A.J.M. Como as famílias utilizam a Educação Financeira. XII Simpósio de Excelência em Gestão e Tecnologia. Associação Educacional Dom Bosco. Resende: Rio de Janeiro. Outubro de 2015.

RAMOS, M.; COPPOLA, N. O Uso do Computador e da Internet como Ferramentas Pedagógicas, 2011. Disponível em:

http://www.diaadiaeducacao.pr.gov.br/portals/pde/arquivos. Acesso em: 20/06/2018.

SILVA, A. M. da; POWELL, A. B. Educação Financeira na Escola: A perspectiva da Organização para Cooperação e Desenvolvimento Econômico. Boletim GEPEM, UFRRJ. Rio de Janeiro. n. 66, jan/jun, p. 3-19, 2015.

STEPHANI, M. Educação Financeira: uma perspectiva interdisciplinar na construção da autonomia do aluno. Dissertação (Mestrado em Educação). Pontifícia Universidade Católica do Rio Grande do Sul. Porto Alegre - RS: PUCRS, 2005. 